\title{
A Complex Permittivity Based Sensor for the Electrical Characterization of High-Voltage Transformer Oils
}

\author{
Constantine T. Dervos ${ }^{1, *}$, Christos D. Paraskevas ${ }^{1}$, Panayotis D. Skafidas ${ }^{1}$ and Panayota \\ Vassiliou $^{2}$ \\ ${ }^{1}$ School of Electrical and Computer Eng., National Technical University of Athens, 9, Iroon \\ Polytechniou Str, Zografou 157 80, Athens, Greece \\ ${ }^{2}$ School of Chemical Eng., National Technical University of Athens, 9, Iroon Polytechniou Str, \\ Zografou 157 80, Athens, Greece
}

*Author to whom correspondence should be addressed. E-mail: cdervos@central.ntua.gr, tel: +30 210 7722577

Received: 28 July 2004 / Accepted: 30 March 2005 / Published: 24 May 2005

\begin{abstract}
This work investigates the use of a specially designed cylindrical metal cell, in order to obtain complex permittivity and $\tan \delta$ data of highly insulating High Voltage (HV) transformer oil samples. The data are obtained at a wide range of frequencies and operation temperatures to demonstrate the polarization phenomena and the thermally stimulated effects. Such complex permittivity measurements may be utilized as a criterion for the service life prediction of oil field electrical equipment (OFEE). Therefore, by one set of measurements on a small oil volume, data may be provided on the impending termination, or continuation of the transformer oil service life. The oil incorporating cell, attached to the appropriate measuring units, could be described as a complex permittivity sensor. In this work, the acquired dielectric data from a great number of operating distribution network power transformers were correlated to corresponding physicochemical ones to demonstrate the future potential employment of the proposed measuring technique.
\end{abstract}

Keywords: dielectric spectroscopy, polarization effects, transformer oils, tan $\delta$, insulation aging. 


\section{Introduction}

Electrical power transformers are used to step up or step down voltage and are an integral component of any efficient power distribution network. A typical transformer incorporates coils of conducting wire wrapped around a core and covered with a paper-based insulator. Essential to the operation of these units are transformer oils that serve both functions: electrical insulation and heat dissipation. Regrettably, there are instances of transformers failing whilst in service, creating significant cost implications for the power supplier and, in extreme cases, explosion with a consequent threat of workers for severe injury or death and significant environmental impacts.

Transformer life/aging is mainly related to the degradation of the insulation, caused mainly by the thermal stress of the insulating paper [1], together with the electrochemical decomposition of the paper. The generated byproducts within the insulating liquids are water and other substances of partly polarizable and ionizable character [2]. For example, the life of insulating cellulose paper at $110^{\circ} \mathrm{C}$ is calculated as only 10 years [3] but it may significantly be extended for lower operating temperatures. Aging depends not just on loading, but is also influenced significantly by the type of paper, pulp composition, humidity and oxygen contents, as well as the acidity level of the insulating liquid. Occasionally failures occur in Ultra High Voltage (UHV) and HV transformers due to streaming electrification [4]. These have been attributed to electrical charges, which are generated at the interfaces between the moving insulating oil and the solid insulating materials of the power transformer with forced cooling.

The most significant physicochemical tests that are frequently performed on insulating transformer oils, are summarized in Table 1.

Additionally, High Performance Liquid Chromatography (HPLC) technique has been recently proposed towards the identification and detection of dissolved or generated gases within the liquid insulation (i.e. $\mathrm{H}_{2}$, methane, hydrocarbons), thus obtaining information on oil dissociation and on the overall status of the component [5-6].

This work exploits the dielectric spectroscopy as a possible alternative diagnostic tool for the usually employed physicochemical and electrical tests that are periodically used on the highly insulating transformer oils.

\subsection{Service-life estimation based on complex permittivity}

The complex permittivity $\left(\varepsilon^{*}\right)$ describes the dielectric properties of the materials (solids and liquids) [7-8] which are classified as 'dielectrics', i.e. they have the ability to store electrical energy, when an external electric field is applied. When an external voltage source is applied across a parallel plate capacitor incorporating the material under test, the enclosed material will polarize to a varying extent at different frequencies, depending on the incorporated contaminants and their related relaxation mechanisms. Dielectric materials increase the energy storage of the capacitor by neutralizing charges at the electrodes. As a result, more charges will flow when a dielectric is positioned between the plates of the capacitor. When an AC sinusoidal voltage source, $\mathrm{u}(\mathrm{t})=\mathrm{V} \cdot \sin (\omega \mathrm{t})$, is applied across the 
capacitor, the resulting current will be made up of two components: the charging current and the loss current, both being related to the complex permittivity. A lossy capacitor can be represented as a conductance $(\mathrm{G})$ in parallel with a capacitance $(\mathrm{C})$. The current flowing through the capacitor is the charge current $\left(\mathrm{I}_{\text {charge }}\right)$ and the current flowing through the conductance is the loss current $\left(\mathrm{I}_{\text {loss }}\right)$, as shown in Fig. 1. For the ideal insulating material, any ac current should only flow through the capacitor.

Table 1. Physicochemical tests commonly performed on insulating transformer oils.

\begin{tabular}{|c|c|c|c|c|}
\hline \multirow{3}{*}{ Test } & \multicolumn{4}{|c|}{ Mineral oils } \\
\hline & \multirow{2}{*}{$\begin{array}{l}\text { ASTM } \\
\text { Method }\end{array}$} & \multicolumn{3}{|c|}{ Aged oils in electrical equipment * } \\
\hline & & $\begin{array}{l}69 \mathrm{kV} \text { and } \\
\text { Below }\end{array}$ & $\begin{array}{c}\text { Above } 69 \mathrm{kV} \\
\text { through } 288 \mathrm{kV}\end{array}$ & $\begin{array}{c}345 \mathrm{kV} \text { and } \\
\text { Above }\end{array}$ \\
\hline $\begin{array}{l}\text { Dielectric breakdown, } \\
\text { (kV min.) }\end{array}$ & D877 & 26 & 26 & 26 \\
\hline $\begin{array}{l}\text { Interfacial tension, } \\
\text { (dynes/cm min.) }\end{array}$ & D971 & 24 & 26 & 30 \\
\hline $\begin{array}{l}\text { Neutralization number, } \\
\text { (mg KOH/g max.) }\end{array}$ & D974 & 0.2 & 0.2 & 0.1 \\
\hline $\begin{array}{l}\text { Water content, } \\
\text { (ppm max.) }\end{array}$ & D1533 & 35 & 25 & 20 \\
\hline Relative density & D1298 & \multicolumn{3}{|c|}{$0.840-0.900 * *$} \\
\hline Color & D1500 & \multicolumn{3}{|c|}{$0.5-8$} \\
\hline
\end{tabular}

* After: InterNational Electrical Testing Association (NETA), "Maintenance Testing Specifications for Electrical Power Distribution Equipment and Systems", 2001.

** The data are mean value obtained from many manufacturers.

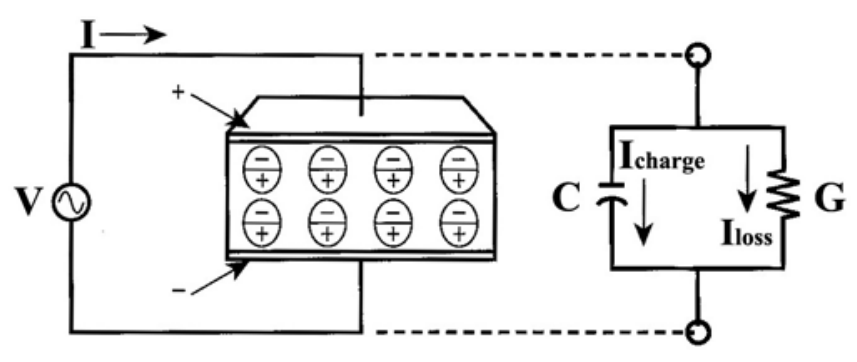

Figure 1. The equivalent circuit of the parallel plate capacitor incorporating the material under test (liquid or solid). 
The total current flowing through the insulator will be given by:

$$
\mathrm{I}=\mathrm{I}_{\text {charge }}+\mathrm{I}_{\text {loss }}=\mathrm{V} \cdot(\mathrm{j} \cdot \omega \cdot \mathrm{C}+\mathrm{G})
$$

where $\mathrm{C}$ is the capacitance with the material under test between the parallel electrodes and $\mathrm{C}_{0}$ is the vacuum capacitance (without the material). Let $C=\varepsilon_{\mathrm{r}}{ }^{\prime} \cdot \mathrm{C}_{\mathrm{o}}$ and $\mathrm{G}=\omega \cdot \mathrm{C}_{\mathrm{o}} \cdot \varepsilon_{\mathrm{r}}{ }^{\prime \prime}$, then,

$$
\begin{aligned}
& \mathrm{I}=\mathrm{V} \cdot\left(\mathrm{j} \cdot \omega \cdot \mathrm{C}_{\mathrm{o}} \cdot \varepsilon_{\mathrm{r}}{ }^{\prime}+\omega \cdot \mathrm{C}_{\mathrm{o}} \cdot \varepsilon_{\mathrm{r}}{ }^{\prime \prime}\right)=\mathrm{V} \cdot\left(\mathrm{j} \cdot \omega \cdot \mathrm{C}_{\mathrm{o}}\right)\left(\varepsilon_{\mathrm{r}}{ }^{\prime}-\mathrm{j} \cdot \varepsilon_{\mathrm{r}}{ }^{\prime \prime}\right)=\mathrm{V}\left(\mathrm{j} \cdot \omega \cdot \mathrm{C}_{\mathrm{o}}\right) \cdot \varepsilon_{\mathrm{r}}{ }^{*} \\
& \varepsilon_{\mathrm{r}}{ }^{*}=\varepsilon_{\mathrm{r}}{ }^{\prime}-\mathrm{j} . \varepsilon_{\mathrm{r}}{ }^{\prime \prime}
\end{aligned}
$$

where

$$
\varepsilon_{\mathrm{r}}^{*}=\varepsilon^{*} / \varepsilon_{\mathrm{o}}
$$

The relative complex permittivity $\left(\varepsilon_{\mathrm{r}}{ }^{*}\right)$ is a dimensionless quantity, which compares the complex permittivity of a material $\left(\varepsilon^{*}\right)$ to the permittivity of the free space $\left(\varepsilon_{0}=8.85410^{-12} \mathrm{~F} / \mathrm{m}\right)$. It describes the interaction of a material with the electric field and consists of a real part $\varepsilon_{\mathrm{r}}{ }^{\prime}$, which represents the storage, and an imaginary part $\varepsilon_{\mathrm{r}}^{\prime \prime}$, which represents the losses.

The real part of the relative permittivity $\left(\varepsilon_{\mathrm{r}}^{\prime}\right)$ is a measure of how much energy from an external electric field will be stored by the material and it is frequently referred as the "dielectric constant". For most solids and liquids $\varepsilon_{\mathrm{r}}^{\prime}>1$. The imaginary part of the relative permittivity $\left(\varepsilon_{\mathrm{r}}{ }^{\prime \prime}\right)$ is called the "loss factor". It is a measure of how dissipative or lossy a material can be to an external electric field. According to the theory, $\varepsilon_{\mathrm{r}}{ }^{\prime \prime}$ is always $>0$ and is usually much smaller than $\varepsilon_{\mathrm{r}}{ }^{\prime}$. When the relative complex permittivity is drawn as a simple vector diagram, the real and imaginary components are $90^{\circ}$ out of phase, (Fig. 2). The vector sum $\varepsilon_{\mathrm{r}}{ }^{*}$ forms an angle $\delta$ with the real axis $\left(\varepsilon_{\mathrm{r}}{ }^{\prime}\right)$. The relative "lossiness" of the material is the ratio of the energy lost to the energy stored.

$$
\tan \delta=\mathrm{I}_{\text {loss }} / \mathrm{I} \text { charge }=\varepsilon_{\mathrm{r}}{ }^{\prime \prime} / \varepsilon_{\mathrm{r}}{ }^{\prime}=\varepsilon^{\prime \prime} / \varepsilon^{\prime} \approx(\text { Energy lost per cycle }) /(\text { Energy stored per cycle })
$$

The $\tan \delta$ is also mentioned as loss tangent, or dissipation factor.

In the event of highly insulating materials, i.e., having very low losses, as is the case of insulating transformer oils, vector $\varepsilon_{\mathrm{r}}{ }^{*} \rightarrow \varepsilon_{\mathrm{r}}{ }^{\prime}$ and $\tan \delta \rightarrow+0$. However, when the $\left|\varepsilon_{\text {error }}\right|$ of the measuring set-up becomes greater than the $\left|\varepsilon_{\mathrm{r}}{ }^{\prime \prime}\right|$ of the material under test, the overall angle $\left(\delta_{\text {error }}\right)$ may become negative, i.e. $\tan \delta \rightarrow-0$ [9]. This is the major parameter that has to be considered in selecting the appropriate measuring sensor for the case of complex permittivity measurements of highly insulating materials. To overcome this difficulty, the sensor geometry and material selection will have to intensify the signal of the $\mathrm{I}_{\text {loss }}$ component in order to be measured by a high precision LCR bridge in a wide frequency range. This may be practically attained either by enhanced electrode areas, or appropriate material and geometry selection of the measuring cell. 


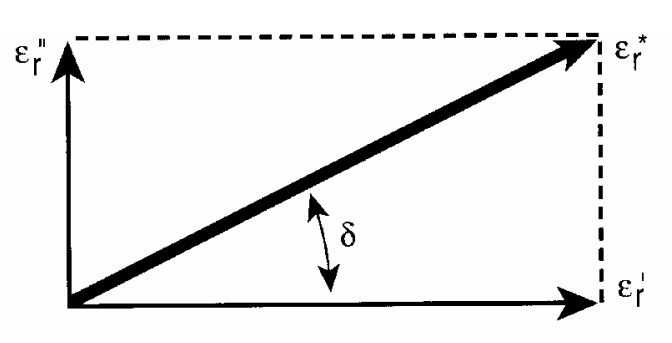

( a )

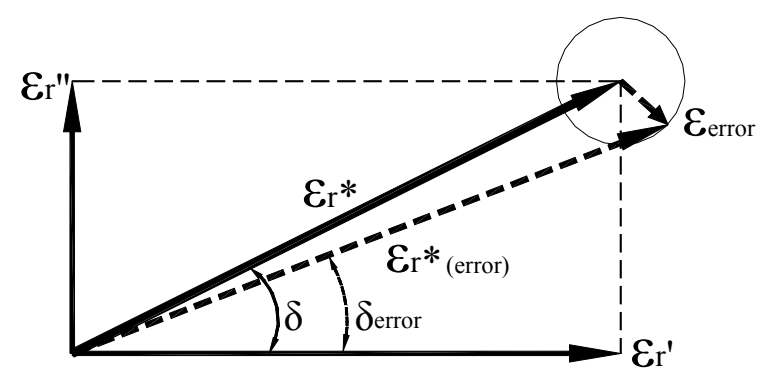

( b )

Figure 2. The complex relative permittivity vector diagram. (a) The angle $\delta$ definition according to eq.5. (b) During permittivity measurements an error vector ( $\varepsilon_{\text {error }}$ ), related to the experimental set-up, is always added to the relative complex permittivity vector. This vector becomes significant only for highly insulating materials, because $\left|\varepsilon_{\mathrm{r}}{ }^{\prime \prime}\right| \rightarrow 0$ and becomes comparable to $\left|\varepsilon_{\text {error }}\right|$.

The complex permittivity is both frequency and temperature dependent. In the low frequency regime ( $\leq 1 \mathrm{MHz}$ ) the ionic and molecular polarization processes are expected to dominate. A temperature rise of the material intensifies losses and the thermally stimulated charge transport processes provide additional current components, thus affecting the overall electrical properties. The investigation of dielectric response as a function of frequency and temperature is known as "temperature dependent dielectric spectroscopy" [10]. The advantage of this approach is that this method can be used as a stand-alone criterion to provide insight information of the insulation status of the HV transformers. Most of the generated byproducts are either polar or ionic, therefore, the dielectric spectroscopy data take under consideration all possible undergoing degradation mechanisms within the component [11].

\section{Experimental Setup}

A high precision LCR meter (type HP 4284A equipped with option 001) has been used to measure complex permittivity variations at a frequency range between $20 \mathrm{~Hz}$ and $1 \mathrm{MHz}$. A coaxial cylindrical stainless steel cell (Figure 3) that could be considered as the complex permittivity sensor for the highly insulating liquids was used to host the examined oil under test. The cell consisted of two electrically isolated stainless steel cylindrical electrodes, $\mathrm{A}$ and $\mathrm{B}$, thus forming the cylindrical capacitor shown in Figure 3. Parts 1 and 6 form the A electrode. Part 7, also utilized as the oil reservoir forms the B electrode. Between electrodes A and B, the incorporated two insulators (parts 2 and 4) are used to allow for a grounded guard-ring formation (part 3). The conical metal ring (part 5) was used for precise height positioning of the inner electrical electrode, thus offering a stable overall assembly of the entire test fixture. 


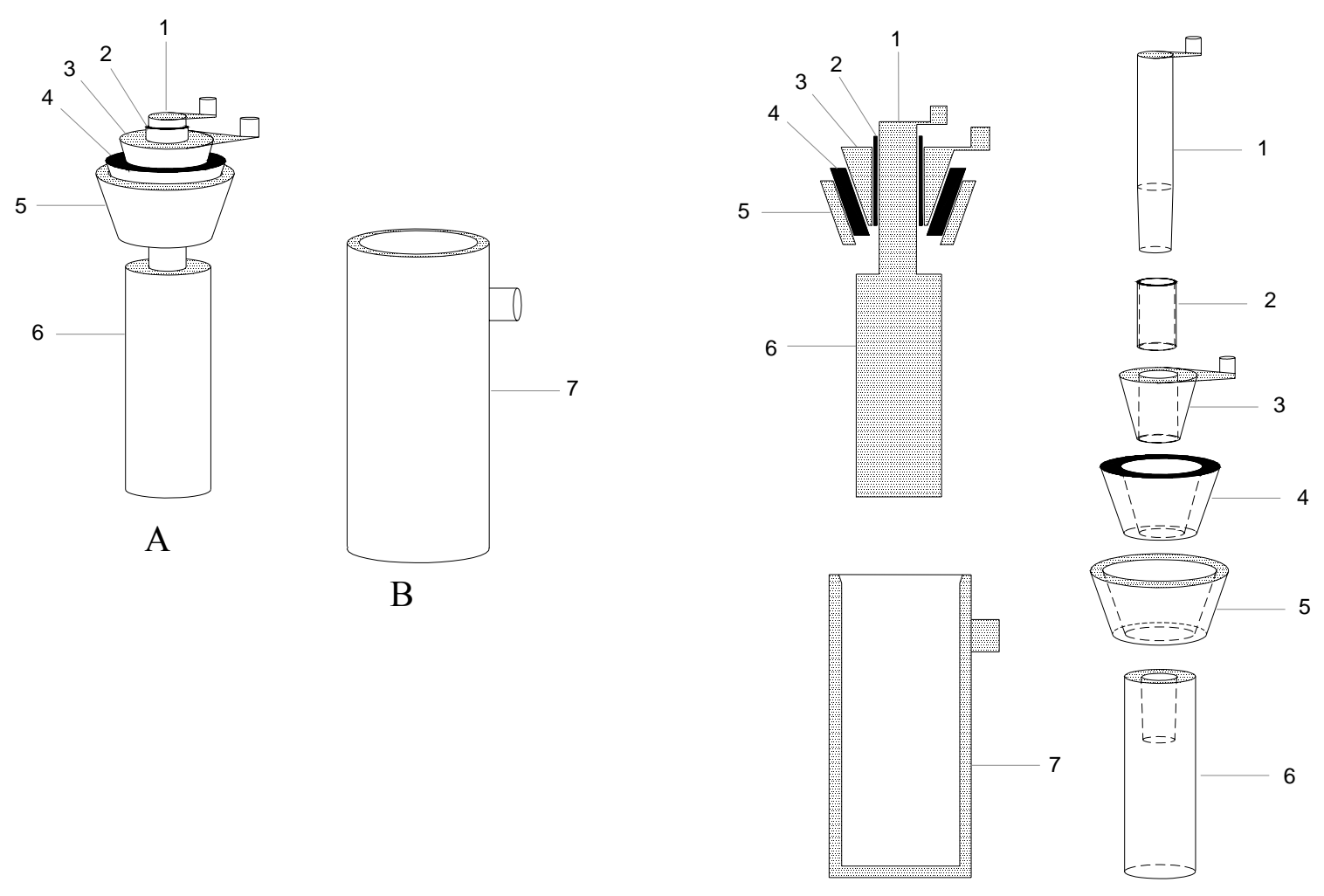

Figure 3. Liquid test fixture proposed for measuring the complex permittivitiy of highly insulating petrochemical products. (a) The overall view of the inner coaxial electrode A and the outer electrode B. (b) The cross-section of the two electrodes and the various parts of the inner electrode assembly.

1: Part 1 of electrode A, 2: PTFE insulator, 3: Guard ring, 4: XLPE conical insulator, 5: Conical metal ring, 6: Part 2 of Electrode A, 7: Electrode $\mathrm{B}$ - oil container.

It was confirmed experimentally that the above cylindrical test fixture offers certain practical advantages over the usually proposed parallel plate fixtures for dielectric measurements of highly insulating liquids. These are mainly attributed to the following facts: (i) provided low-loss solid insulators are incorporated in the cell construction the overall attained conductance between the measuring electrodes in air will be very low and (ii) for the two different measuring geometries, i.e. cylindrical versus parallel, under a given electrode spacing and oil volume, the cylindrical geometry obtains stable conductance values for the corresponding C-G parallel equivalent circuit. The aforesaid statements were experimentally confirmed.

The measuring cell was placed in a temperature-controlled chamber (Weiss Tecknick KWP64) that enabled temperature variations between $-20^{\circ} \mathrm{C}$ and $+120^{\circ} \mathrm{C}$. The sample holder contained $15 \mathrm{ml}$ of the examined liquid and it was electrically connected by a four terminal configuration to the high precision LCR measuring unit. To avoid thermovoltage formation due to thermal differences across the measuring leads, the high temperature connecting leads (Agilent 16452-61601) were used for connecting the cell to the LCR terminals. All measuring units (LCR meter, cell and temperature 
controllers) were computer controlled by the IEEE-488.2 interface-bus, thus enabling automated measuring procedures to run by a C-based software application. The overall experimental setup is shown in Fig. 4.

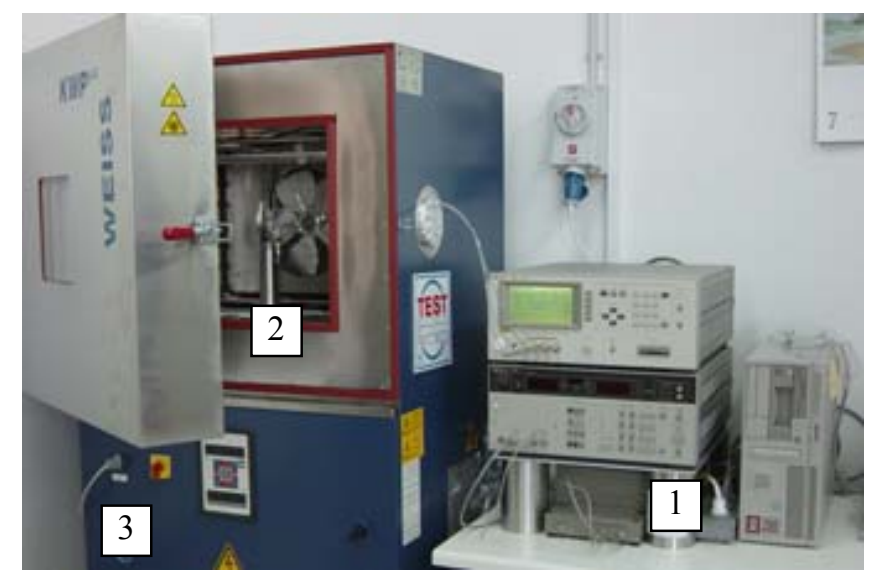

Figure 4. The experimental setup used for measuring multi-frequency temperature dependent complex permittivity values of highly insulating transformer oils: (1) high precision LCR unit, (2) the coaxial cylindrical test fixture, and (3) temperature controlled environmental chamber. All units were computer controlled.

\section{Results and Discussion}

\subsection{The examined samples}

For the purpose of this work, measurements were performed on oil samples, obtained from 201 power distribution transformers of the $150 \mathrm{kV}$ and $400 \mathrm{kV}$ network of the Public Power Corporation of Greece. The followed sampling procedure is described by ASTM D117-02 Standard Guide for Sampling, Test Methods and Specifications for Electrical Insulating Oils of Petroleum Origin and ASTM-D923-97 concerning Practices for Sampling Electrical Insulating Liquids.

\subsection{Typical dielectric spectroscopy results}

The theoretical model describing the permittivity evaluation of materials vs. frequency and temperature, implies that any good quality oil sample will be characterized by a low $\varepsilon_{\mathrm{r}}{ }^{\prime}$ value (ideally $\varepsilon_{\mathrm{r}}{ }^{\prime} \rightarrow 1$ ) and a low $\varepsilon_{\mathrm{r}}{ }^{\prime \prime}$ value (ideally $\varepsilon_{\mathrm{r}}{ }^{\prime \prime} \rightarrow 0$ ) and therefore, $\tan \delta \rightarrow 0$ at all frequencies. In the absence of polarization processes these results should be temperature independent, implying that the examined samples are high purity oils being entirely free of aging byproducts or contaminants. For the purpose of this study the permittivity measurements were performed under four different oil temperatures, i.e. $20^{\circ} \mathrm{C}, 40^{\circ} \mathrm{C}, 60^{\circ} \mathrm{C}$ and $80^{\circ} \mathrm{C}$. Such oil temperatures may be practically encountered around the hot spot regions of high power transformers. 
Table 2. Oil group classification in terms of permittivity characterization.

\begin{tabular}{|c|l|}
\hline Group-I & Oils that are in satisfactory condition for continued usage. \\
\hline Group-II & $\begin{array}{l}\text { Oils that may need reconditioning (dehydration/filtration) to ensure prolonged and } \\
\text { reliable service. }\end{array}$ \\
\hline Group-III & $\begin{array}{l}\text { Oils in poor condition. Such oils should be either reclaimed for possible recondi- } \\
\text { tioning, or disposed. Components may require frequent inspection and decision has } \\
\text { to be taken in order to undergo servicing, depending on economic considerations. }\end{array}$ \\
\hline
\end{tabular}

Previous work [12-13] has established that the temperature dependent complex permittivity measurements at various frequencies can be utilized to validate the insulation capacity of power transformer oils. The proposed criteria for sample dielectric characterization were based upon the values of $\varepsilon_{\mathrm{r}}^{\prime}$ and $\tan \delta$ at $20^{\circ} \mathrm{C}$ and the resulting variations with temperature [13].

According to the above criteria and the obtained complex permittivity results, the investigated samples could be categorized in three distinct groups, as given in Table 2. The resulting classification within each group was found to be as shown in Figure 5.

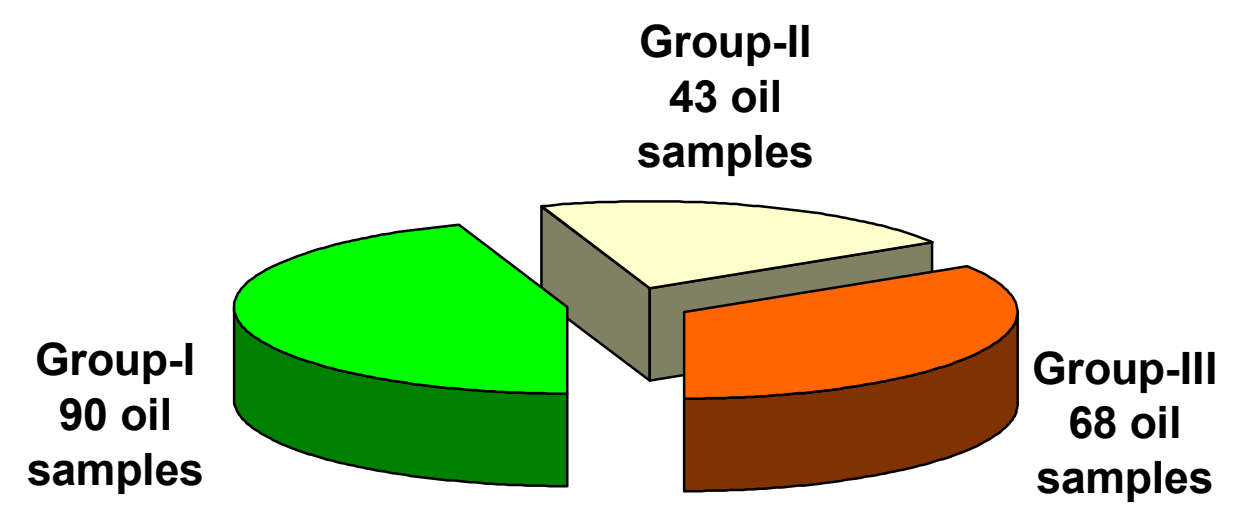

Figure 5. Number of oil samples characterized within each category.

Throughout this work, the circle markers represent data of oil temperature of $80^{\circ} \mathrm{C}$. The triangle markers represent oil temperature of $60^{\circ} \mathrm{C}$. The square markers represent oil temperature of $40^{\circ} \mathrm{C}$ and the rhombic markers represent oil temperature of $20^{\circ} \mathrm{C}$.

3.2.a. Group-I: Oils that are in satisfactory condition for continued usage

These oil samples exhibit low $\varepsilon_{\mathrm{r}}{ }^{\prime}$ values (practically measured to be of the order of $2.15 \pm 0.01$ at $\left.20^{\circ} \mathrm{C}\right)$. As the oil temperature is increased the real part of the relative complex permittivity $\left(\varepsilon_{\mathrm{r}}{ }^{\prime}\right)$ tends to be slightly reduced. Additionally, $\varepsilon_{\mathrm{r}}{ }^{\prime}$ is almost frequency independent (Fig.6a). 
The oil samples of this group are also characterized by the very low tan $\delta$ values, which are measured in the range of $10^{-4}$ to $10^{-3}$ and are temperature independent at all frequencies (Fig. 6b, 6c).

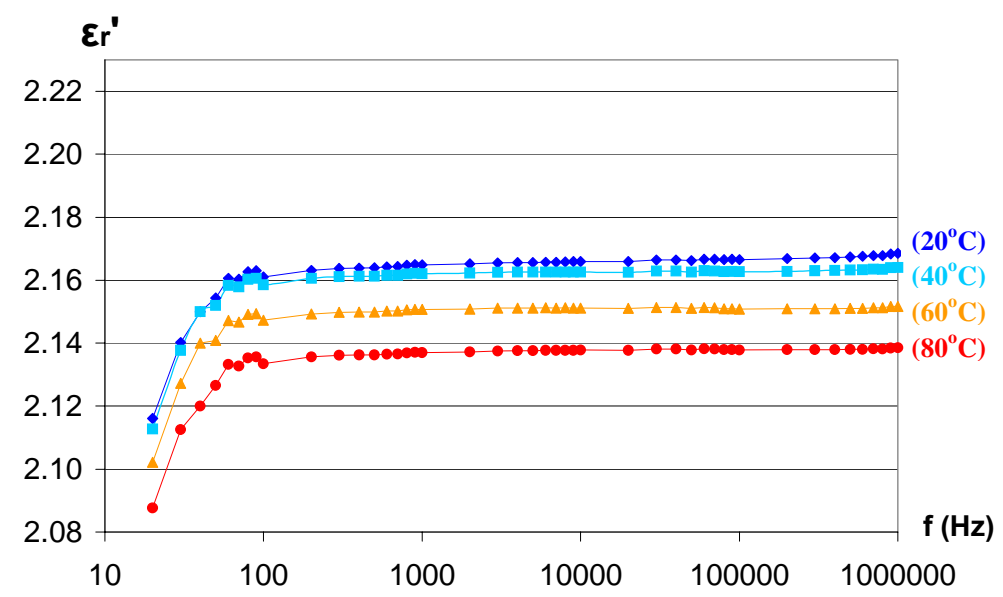

(6a)

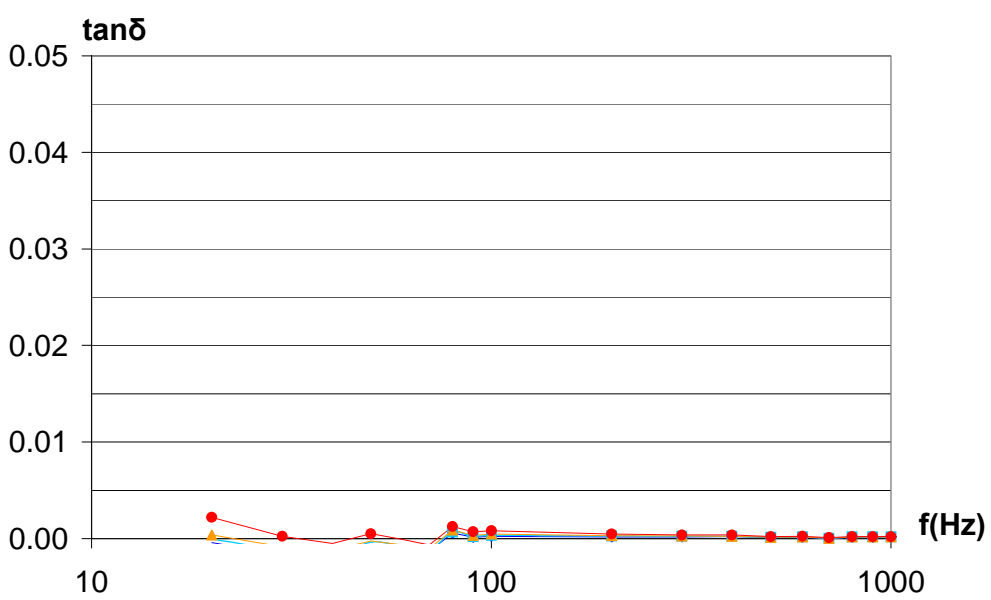

(6b)

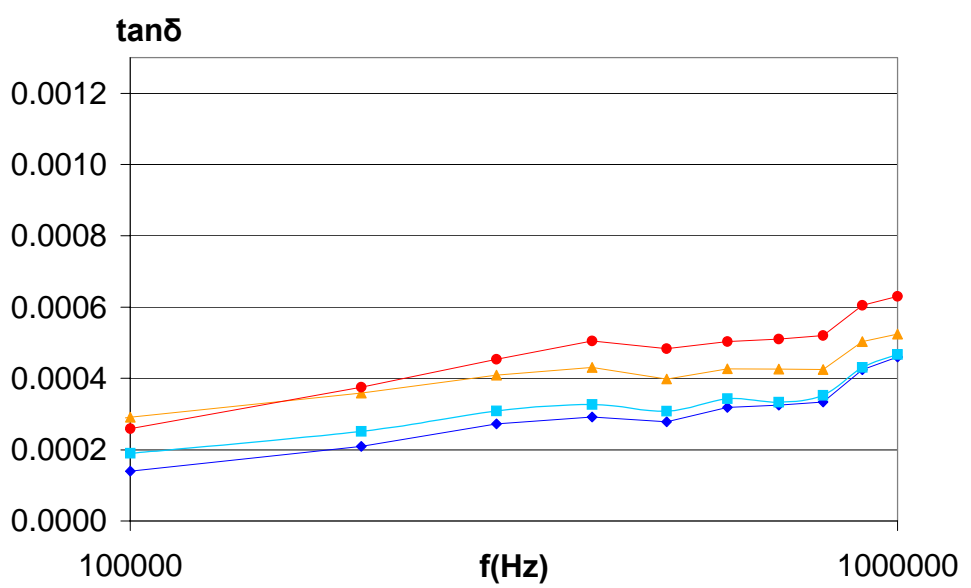

(6c)

Figure 6. The dielectric spectroscopy data of the 90 power transformer oil samples classified in Group-I. (a) The average values for the relative dielectric constant $\left(\varepsilon_{\mathrm{r}}^{\prime}\right)$ of all Group-I samples, as a function of the operating temperature and frequency. (b) The average values of all tan $\delta$ data of the Group-I samples, as a function of temperature in the frequency range: $20 \mathrm{~Hz}-1 \mathrm{kHz}$. (c) The average values of all $\tan \delta$ data of the Group-I samples, as a function of temperature in the frequency range: 100 $\mathrm{kHz}-1 \mathrm{MHz}$. 
3.2.b. Group-II: Oils that may require reconditioning (dehydration/filtration) to ensure a prolonged and reliable service

The oil samples that are categorized in this group may exhibit slight disorders for at least one of the measured dielectric quantities. For example, if an oil sample provides low $\varepsilon_{r}^{\prime}$ and $\tan \delta$ values at high frequency region, but exhibits increased losses and therefore, higher tan $\delta$ values in the low frequency region $(20 \mathrm{~Hz}-1 \mathrm{kHz})$ with slight thermal dependence, it is classified in Group-II oil category.

Fig. 7 provides the average values of the dielectric parameters of the 43 samples within this group. According to these results the real part of the relative permittivity is found to be in the range of $2.19 \pm 0.01$ at $20^{\circ} \mathrm{C}$ while the tan $\delta$ values are only slightly increased to $10^{-3}$ at $20^{\circ} \mathrm{C}$ and show minor temperature dependence at lower frequencies (Fig. 7b). All figures (Figure 7, Figure 8 and Figure 9) are presented with same scales to enable for a direct comparison between corresponding data of oil samples in Groups I, II and III. Notice that for the $\varepsilon_{\mathrm{r}}{ }^{\prime}$ and $\tan \delta$ results of Group-II, the corresponding values are slightly increased at all frequencies and temperatures, compared to the Group-I.

\section{2.c. Group-III: Oil samples in poor condition}

Oil samples in this group are characterized by very high dielectric disorders of at least one of the measured parameters. This could be practically related not only to their relatively high humidity levels, but on the presence of additional polar contaminants and other possible aging (ionic/molecular) byproducts.

The average values of the investigated dielectric parameters of the 68 oil samples characterized in Group-III are given in Figure 8. Here, the $\varepsilon_{\mathrm{r}}{ }^{\prime}$ values are increased and are found to be in the range of $2.21 \pm 0.01$ at $20^{\circ} \mathrm{C}$. The tan $\delta$ values are increased up to $10^{-2}$ level for oil temperatures of $20^{\circ} \mathrm{C}$ and the conductance results exhibit strong temperature dependence at all frequencies, especially in the lower frequency regime $(20 \mathrm{~Hz}-1 \mathrm{kHz})$ where the ionic relaxation dominates.

The incorporated various byproduct concentrations mainly affect current losses and therefore, the overall $\tan \delta$ values. The loss current intensification can be attributed to the polarizable inclusions originating from various sources, i.e. cellulose paper aging byproducts, chemically etched copper ions originating from the transformer windings due to the acidic oil media, ash formation by the oil degradation, gaseous byproducts created during dissociation of the transformer oil, etc. Presently, these byproduct concentrations require physicochemical and analytical techniques [5-6] to be uniquely identified, but without indicating trends towards total breakdown voltage deterioration input which is of primary concern. On the contrary, the direct measurement of electrical losses brings-in vital information concerning possible breakdown onset. 


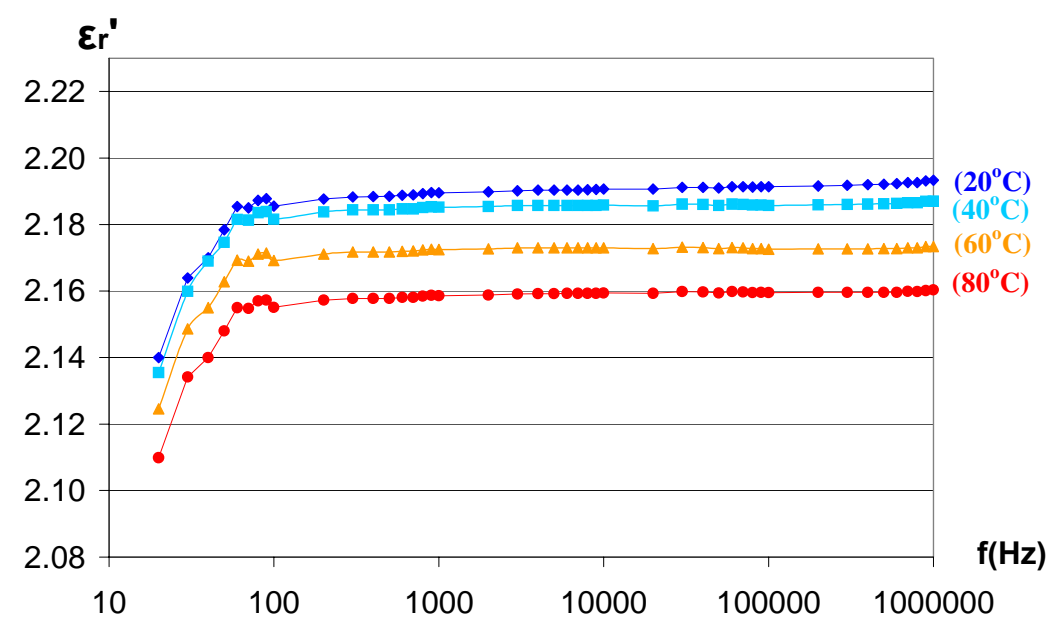

(7a)

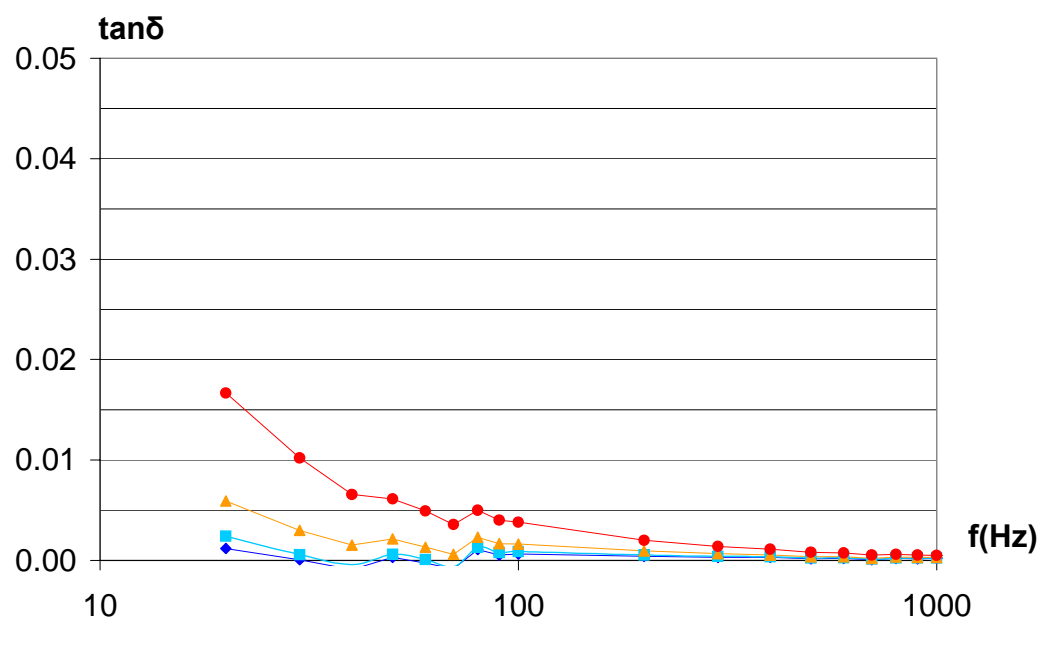

(7b)

$\tan \delta$

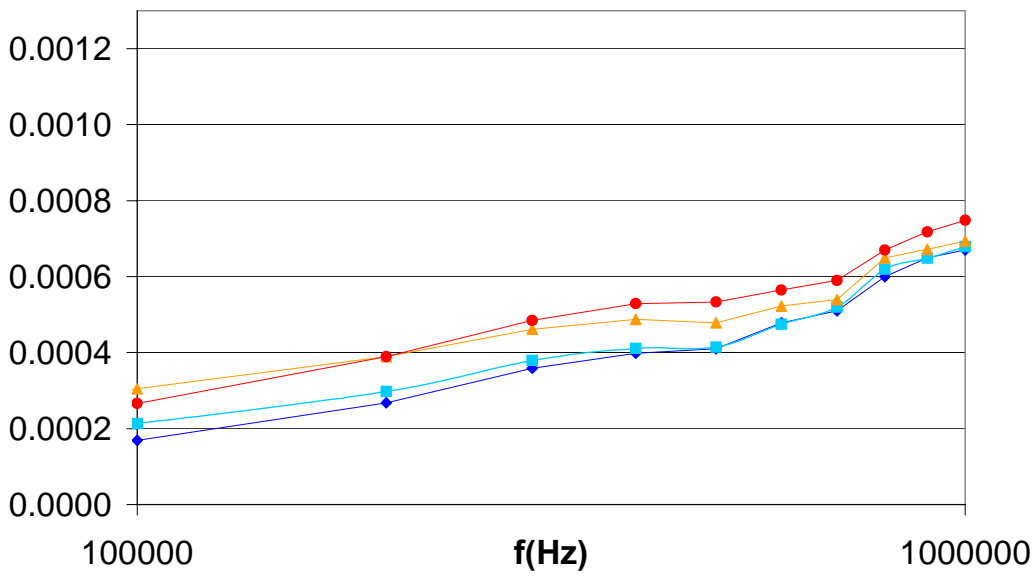

(7c)

Figure 7. The dielectric spectroscopy data of the 43 power transformer oil samples classified in Group-II. (a) The average values for the relative dielectric constant $\left(\varepsilon_{\mathrm{r}}{ }^{\prime}\right)$ of all Group-II samples, as a function of the operating temperature and frequency. (b) The average values of all loss $\operatorname{tangent}(\tan \delta)$ data of the Group-II samples, as a function of operating temperature in the frequency range: $20 \mathrm{~Hz}-$ $1 \mathrm{kHz}$. (c) The average values of all loss tangent $(\tan \delta)$ data of the Group-II samples, as a function of operating temperature in the frequency range: $100 \mathrm{kHz}-1 \mathrm{MHz}$. 


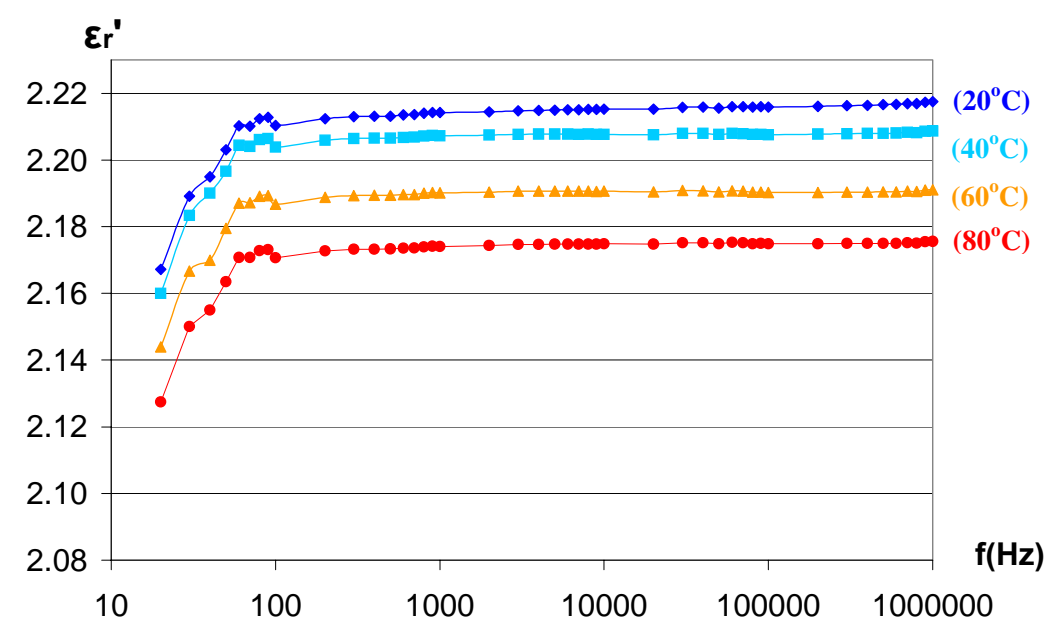

(8a)

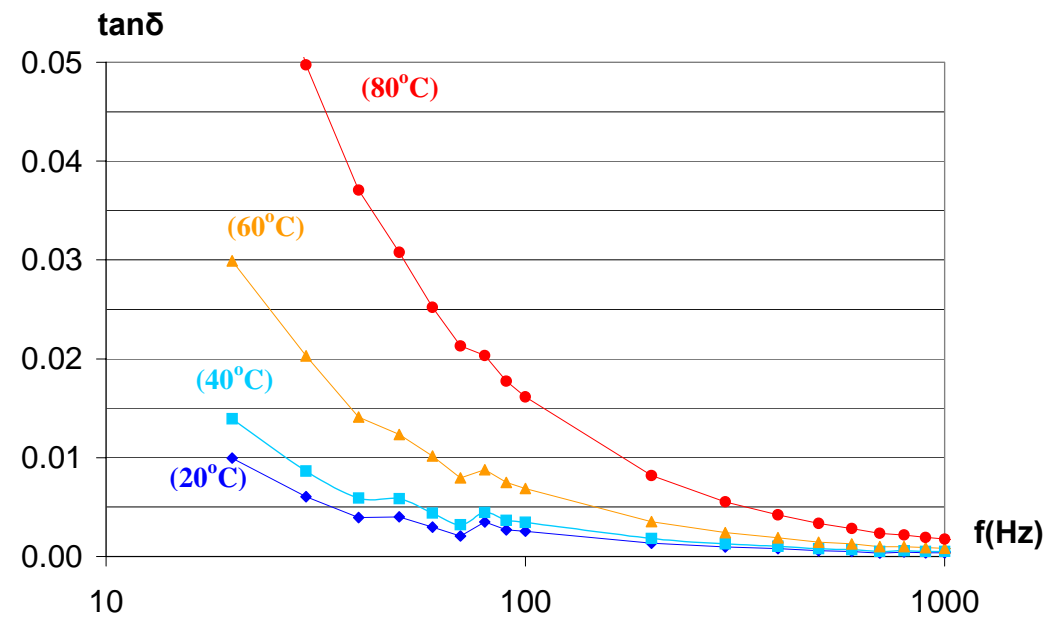

(8b)

(8c)

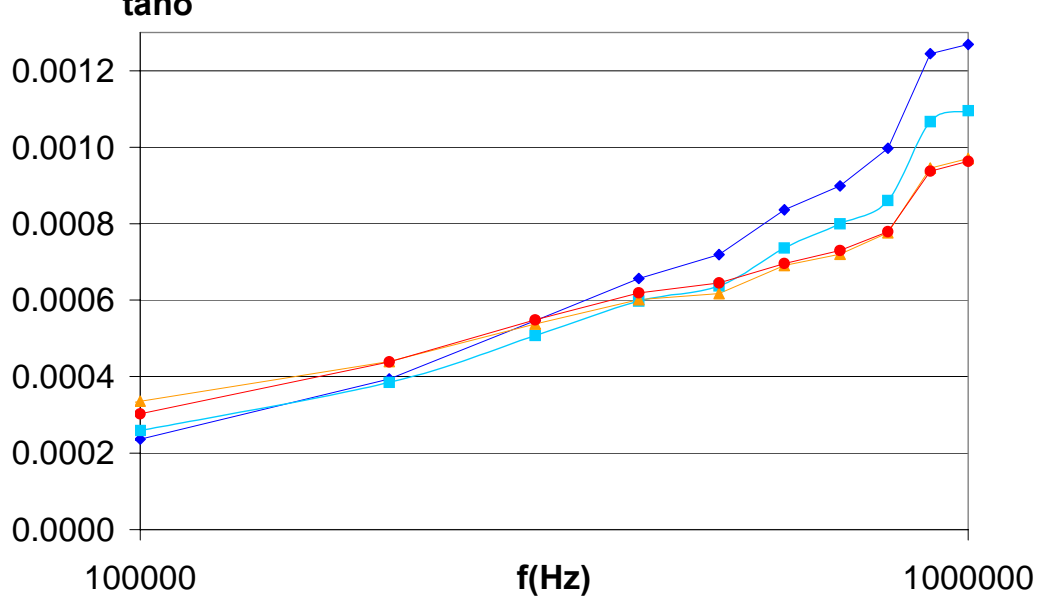

Figure 8. The dielectric spectroscopy data of the 68 power transformer oil samples classified in Group-III. (a) The average values for the relative dielectric constant $\left(\varepsilon_{\mathrm{r}}{ }^{\prime}\right)$ of all Group-III samples, as a function of the operating temperature and frequency. (b) The average values of all loss tangent $(\tan \delta)$ data of the Group-III samples, as a function of operating temperature in the frequency range: $20 \mathrm{~Hz}-$ $1 \mathrm{kHz}$. (c) The average values of all loss tangent $(\tan \delta)$ data of the Group-III samples, as a function of operating temperature in the frequency range: $100 \mathrm{kHz}-1 \mathrm{MHz}$. 


\subsection{The corresponding physicochemical results}

The physicochemical tests described in Table 1 were performed in every mineral oil sample according to the corresponding ASTM procedure. Then, the average values of estimated physicochemical entities of all samples incorporated in each Group (I, II, and III) were evaluated, as shown in Fig. 9.

Fig. 9a provides the average breakdown voltage under given electrode geometry as prescribed by the ASTM D877. According to these results there is a clear tendency for breakdown voltages to be reduced in oil samples having deteriorating permittivity characteristics. The acquired average breakdown voltage values for all Groups are above the $26 \mathrm{kV}$ threshold, which is frequently considered as the minimum requirement for used oils. However, close comparison between samples might lead to the conclusion that this physicochemical measurement cannot be used as a stand alone prediction measurement of the expected oil service-life since in some of the Group-III samples the acquired dielectric breakdown values were high enough $(\sim 31 \mathrm{kV})$.

Fig. $9 \mathrm{~b}$ provides the average acidity levels of oils within each group, as determined by the ASTM D974, i.e. number of $\mathrm{mg}$ of $\mathrm{KOH}$ required to neutralize one $\mathrm{g}$ from each oil sample. According to the results of Fig. 9.b. the acidity values are increased as the permittivity characteristics of the oil samples deteriorate, i.e. Group-III oil samples show higher acidity levels compared to the oil samples in GroupII and Group-I. The quoted average acidity values satisfy the maximum threshold requirement of $0.2 \mathrm{mg} \mathrm{KOH} /$ oil g, but distinct samples exist in Group-III where the acidity exceeds $0.3 \mathrm{mg} \mathrm{KOH} /$ oil g. Acidity depends on aging byproducts, as well as on the concentration of additives, e.g. possible P.C.B. content in the oil matrix above $50 \mathrm{ppm}$.

Fig. 9c provides the interfacial tension values for oils within each group (I, II, and III). Measurements were performed according to the ASTM D971. According to the results of Fig. 9c. the interfacial tension decreases as the permittivity characteristics of the oil samples deteriorate, i.e. Group-III oil samples exhibit lower interfacial tension compared to oil samples in Group-II and GroupI. Oil samples in Group-I have values within the suggested limits, while samples of Group II have values close to the minimum requirement of 24 dynes/cm and Group III samples exhibit unacceptable interfacial tension values $(<24$ dynes/cm). These results are in good accordance with the dielectric spectroscopy data and therefore, interfacial tension measurements can be utilized as a reliable approach for the overall oil condition.

Fig. 9d provides the average values of the relative density for oils within each group (I, II, and III). Measurements were performed according to the ASTM D1298. According to the results of Fig. 9d. the density increases as the permittivity characteristics of the oil samples deteriorate. Though the experimentally obtained density values of all examined samples are at acceptable variations as given by the various manufacturers for aged insulating oils (0.840-0.900), it can be seen that the density values in Group-III oil samples is highly increased. This could be related to the dissociation byproducts incorporated in the oil matrix, i.e. chemical dissociation of insulation paper, etched copper ions [14], free radicals of broken down hydrocarbon chains. 
(9a)

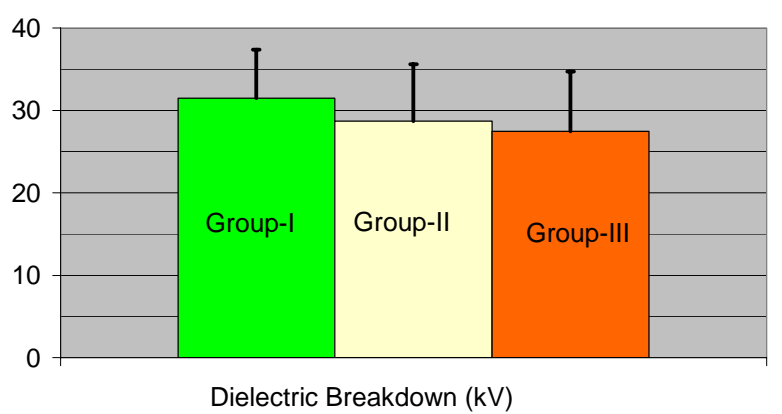

(9b)

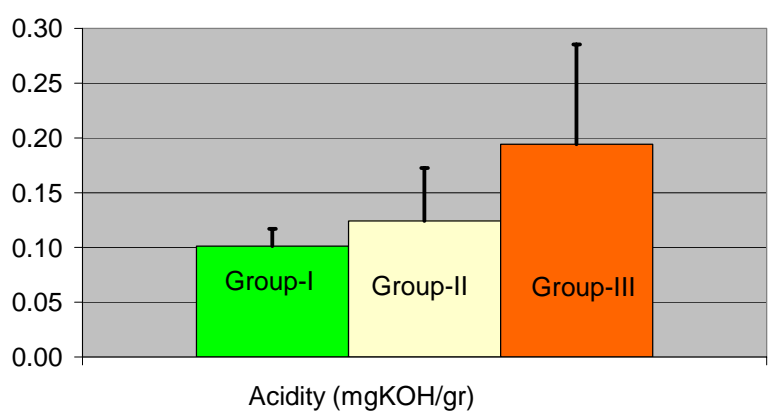

(9c)

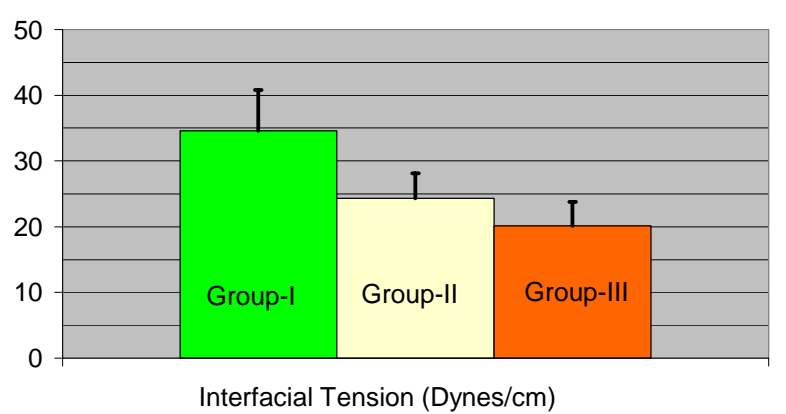

(9d)

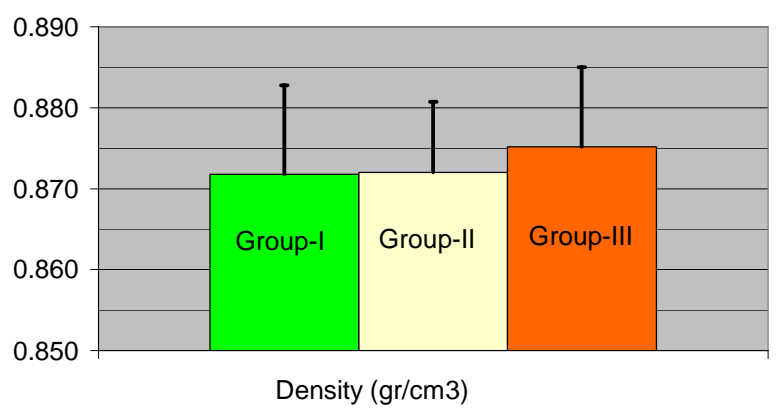

(9e)

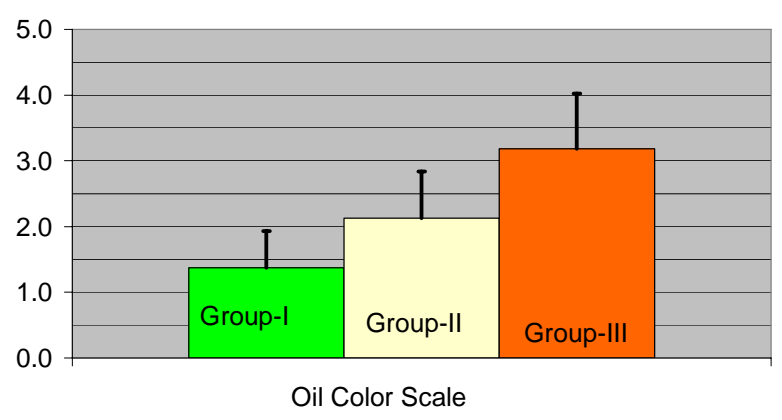

(9f)

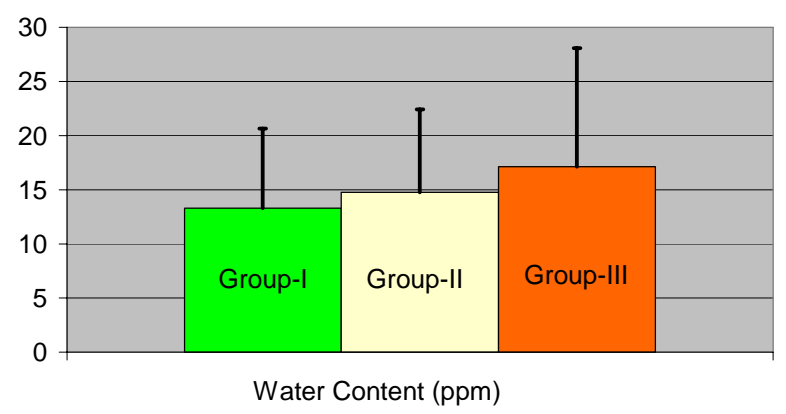

Figure 9. Cumulative average values of measured physicochemical quantities with range of standard deviations (plus) for the examined oil samples within various groups (Group-I, Group-II, Group-III). Group characterization based upon oil permittivity data.
(a) The average breakdown voltage values $(\mathrm{kV})$.
(b) The acidity, average neutralization values ( $\mathrm{m} \mathrm{KOH} / \mathrm{oil} \mathrm{g}$ ).
(c) The average interfacial tension values (dynes $/ \mathrm{cm}$ ).
(d) The average relative density values (as compared to water density).
(e) The average oil color number values (0.5-8.0) according to ASTM D1500.
(f) The water concentration in oil (ppm max.).

Fig. 9e provides, for each group, the average oil color number values (0.5-8.0) as determined by the ASTM D1500. According to the obtained results the oil color number raises as the oil permittivity properties tend to deteriorate. However, it should be emphasized that color is not always a reliable 
guide to product quality and should not be used indiscriminately in product characterization (ASTM D1500).

Fig. 9f provides the average values of the water content in oils (ppm max) within each group (I, II, and III). Measurements were performed as prescribed by the ASTM D1533. According to the results of Fig. 9f, the water concentration (ppm) increases as the permittivity characteristics of the oil samples deteriorate. The maximum allowable concentration of water in used oils is $35 \mathrm{ppm}$ for electrical applications below $69 \mathrm{kV}$. For the $150 \mathrm{kV}$ components the max. water concentration in oil is $25 \mathrm{ppm}$ and for the $400 \mathrm{kV}$ it is $20 \mathrm{ppm}$. It can be noticed from the results presented in Fig. 9f that the average values for all three groups are well below the 20 ppm limits.

Though most of the examined mineral oil samples collected from field operating power transformers fulfill the ASTM requirements of the physicochemical tests given in Table 1, there exist significant variations among their permittivity characteristics. Permittivity differentiations emanate by the polarizable/ionizable aging byproducts within the insulating liquid. During the oil degradation process gases will evolve as the hydrocarbon chains break down leaving large free radicals in the liquid phase [5]. The collisions of such free radicals usually generate large agglomerates of colloidal decay products with an average molecular weight of 450 to 550, that are no longer soluble in oil and precipitate as sludge or ash [2]. The most frequently detected gases by HPLC in transformer mineral oils are $\mathrm{O}_{2}, \mathrm{~N}_{2}, \mathrm{H}_{2}, \mathrm{CH}_{4}, \mathrm{CO}, \mathrm{CO}_{2}, \mathrm{C}_{2} \mathrm{H}_{6}, \mathrm{C}_{2} \mathrm{H}_{4}, \mathrm{C}_{2} \mathrm{H}_{2}, \mathrm{C}_{3} \mathrm{H}_{8}$ and other liquid hydrocarbons [5-6]. Limitations of Dissolved Gas Analysis (DGA) techniques rise by the fact that the Totally Dissolved Gas Compositions (TDGC) cannot be monitored in the liquid, since the gases can be dynamically either evolving or being absorbed, and the measured values will be the net effect of two competitive reactions of the traced specific gases.

On the other hand, the test methods prescribed by the Oxidation Stability of Mineral Insulating Oils in ASTM D2440 require laboratory environment for the time demanding absorbance tests in the visible spectrum.

Therefore, the proposed temperature dependent dielectric spectroscopy acquires direct information concerning the electrical energy loss and storage by the liquid insulation, thus allowing for systematic differentiation monitoring among the operational transformer oils.

\section{Conclusions}

The monitoring of complex permittivity of transformer oils, as a function of frequency and temperature, may provide inside information concerning the state of insulation within the components. In this work, it has been investigated as a quality control method, providing service life estimations of power transformers. The formation of databases recording polarization effects in a wide frequency and temperature range may be used effectively as a working tool for service engineers. Reliable insulation monitoring will diminish accidents in aged HV transformers, some of them being in operation from the $60 \mathrm{~s}$, thus imposing an environmental threat due to possible accidental leaks or fire events especially when containing traces of PCBs. 


\section{Acknowledgments}

The authors wish to thank the Public Power Corporation of Greece for supporting this project.

\section{References}

1. Morgan, V.T. Effects of frequency, temperature, compression, and air pressure on the dielectric properties of a multilayer stack of dry kraft paper. IEEE Trans. on Dielectrics and Elec. Insul. 1998, 5, 125-131.

2. Ferguson, R.; Lobeiras, A.; Sabau, J. Suspended particles in the liquid insulation of aging power transformers. IEEE Electrical Insulation Magazine 2002, 18, 17-23.

3. Borsi, H. Esterfluessigkeit Midel 7131 als Ersatz fuer Mineraloel in Transformatoren. Elektrizitaetswirtschaft, Jg. 93. 1994, 24, 1523-1528.

4. Kanno, M.; Oota, N.; Suzuki, T.; Ishii, T. Changes in ECT and dielectric dissipation factor of insulating oils due to aging in oxygen. IEEE Trans. Dielectrics and Elec. Insul. 2001, 8, 10481053.

5. Duval, M.; DePablo, A. Interpretation of gas-in-oil analysis using new IEC publication 60599 and IEC TC 10 databases. IEEE Electrical Insulation Magazine. 2001, 17, 31-41.

6. Arakelian, V.G. Effective diagnostics for oil-filled electrical equipment. IEEE Electrical Insulation Magazine 2002, 18, 26-38.

7. Goetz, M.P. Permittivity measurements of frequency dependent electronic materials; HewlettPackard Application Note 5964-1506E, CA, USA, 1995.

8. American Standards for Testing Materials, ASTM D150. Test methods for A-C loss characteristics and permittivity (dielectric constant) of solid electrical insulation materials. 1998.

9. Agilent 16452A Liquid Test Fixture, Operating and Service Manual, 3rd Edition, Japan, 2000.

10. Zaengl, W. S. Dielectric Spectroscopy in Time and Frequency Domain for HV Power Equipment, Part I: Theoretical Considerations. IEEE Electrical Insulation Magazine 2003, 19, 5-19.

11. CIGRE Task Force 15.01.09. Dielectric response methods for diagnostics of power transformers. IEEE Electrical Insulation Magazine. 2003, 19, 12-18.

12. Dervos, C.T.; Vassiliou, P.; Skafidas, P.; Paraskevas, Ch. Service life estimation of transformer oil in Proc. Intern. Conf. on Protection and Restoration of the Environment VI, Skiathos, 2002, pp.1239-1246.

13. Dervos, C.T.; Paraskevas, Ch.D.; Skafidas, P.; Vassiliou, P. Dielectric characterization of power transformer oils as a diagnostic life prediction method. IEEE Electrical Insulation Magazine. 2005, 21, 11-19.

14. Castle, J.E.; Whitfield, T.B.; Ali, M. The transport of copper through oil impregnated paper insulation in electrical current transformers and bushings. IEEE Electrical Insulation Magazine 2003, 19, 25-29.

(C) 2005 by MDPI (http://www.mdpi.org). Reproduction is permitted for noncommercial purposes. 